\title{
Habilidades metacognitivas envolvidas na resolução de problemas em Física: Investigando estudantes com expertise
}

Metacognitive abilities involved in Physics problem solving: investigating expertise students

\author{
Cleci Teresinha Werner da Rosa ${ }^{1}$ \\ Cassia de Andrade Gomes Ribeiro ${ }^{2}$ \\ Alvaro Becker da Rosa ${ }^{3}$
}

\section{Resumo}

O presente estudo tem por objetivo identificar a forma como estudantes de Física experts em resolução de problemas estruturam seus pensamentos e recorrem as suas habilidades metacognitivas. Para isso, foram selecionados estudantes de um curso de Física apontado por seus professores como bons resolvedores de problemas. A partir dessa identificação eles foram submetidos a sessões de entrevistas clínicas, nas quais resolveram três problemas de Física e por meio do protocolo de pensamento em voz alta, foi possível obter dados e analisar a forma como organizam o seu pensamento no momento em que resolvem os desafios. Como recorte do estudo, limitou-se a análise em termos das habilidades metacognitivas, especificamente em termos dos elementos: planificação, monitoramento e avaliação. Os resultados apontam para a presença destes elementos e são promissores em termos de fornecer subsídios para a prática docente do professor de Física.

Palavras chave: resolução de problemas; experts; Física; habilidades metacognitivas

\section{Abstract}

The present study has as objective identifying the way how physics' students who are experts in problem solving structure their thoughts and reach to their metacognitive abilities. For that, students from a Physics course who were pointed out by their teachers were selected as good at problem solving. Based on that identification they were submitted to sections of clinical interviewing, where they solved three physics problems and by mean of the protocol of out loud thinking, it was possible to obtain data and analyse the way how their thoughts were organized in the moment that they solved the challenges. As a cut off the study, the analyse was limited in terms of metacognitive abilities, specifically in terms of the elements: planning, monitoring and evaluation. The results point to the presence of these elements and are promising in terms of providing subsidies for the physics teacher's practice.

Keywords: problem solving; experts; Physics; metacognitive abilities

\footnotetext{
1 Universidade de Passo Fundo | cwerner@upf.br

${ }^{2}$ Universidade de Passo Fundo | ribeirocasi@gmail.com

${ }^{3}$ Universidade de Passo Fundo | alvaro@upf.br
} 


\section{Introdução}

A aprendizagem em Física tem sido merecedora de atenção especial por parte dos pesquisadores em face aos resultados pouco promissores apresentados pelos alunos do Ensino Médio, especialmente em provas de larga escala, como o Exame Nacional do Ensino Médio - ENEM. Os dados do Instituto Nacional de Estudos e Pesquisas Educacionais - INEP (2016) mostram que a média dos alunos na área de Ciências da Natureza e suas Tecnologias, onde a Física se encontra presente, estão abaixo das demais áreas do conhecimento.

Tais resultados são indicativos de que os estudantes apresentam dificuldades de aprendizagem nessa área do conhecimento, cujas origens são de diversas naturezas. Dentre elas está à falta de uma compressão efetiva por parte dos alunos com relação aos conceitos e fenômenos abordados nas aulas, como lembra Moreira (2011). Segundo o autor, a memorização dos conteúdos tem sido a tônica das aulas de Física e se revela pouco efetiva na busca por uma aprendizagem significativa e duradoura.

Na busca por mecanismos que auxiliem os estudantes a qualificar seus processos de aprendizagem, estudos têm inferido que o uso dos processos metacognitivos decorrentes desse pensamento, é inerente ao ser humano, pode representar uma alternativa. Esse raciocínio, conforme mencionado por Kluwe (1987) é parte da atividade da cognição humana, bem como parte do próprio sistema cognitivo do indivíduo. Continua o autor mencionando que por pensamento metacognitivo entende-se a ativação de mecanismos mentais internos que permitem ao sujeito refletir e identificar os caminhos que o levaram a pensar ou agir de determinada forma, permitindo regular e controlar suas ações em prol de alcançar êxito em seus objetivos. Em outras palavras, é como menciona Flavell (1976) um pensar sobre o pensar, ou a cognição da cognição.

A utilização dessa forma de pensamento não é espontânea para todos os sujeitos, podendo ou não ser ativada por eles. O que leva um sujeito a recorrer de forma espontânea a esse pensamento permanece uma incógnita nas pesquisas em neurociência, bem como o fato dele ser consciente ou inconsciente nos sujeitos (ROSA, 2014). Entretanto, o que se sabe é que para alguns ele se manifesta de forma espontânea e permite a esses indivíduos lograrem êxito em suas atividades, como a de resolução de problemas em Física, por exemplo. Além disso, ele pode se desenvolver com o tempo ou ser instigado por meio de dinâmicas externas ou mesmo por atividades de instrução em que sua evocação faz parte do objetivo da atividade (MONEREO, 2001).

Na resolução de problemas em Física, estudos como os desenvolvidos por Chi e colaboradores (1982; 1989), Reif e Larkin (1991), Malone (2008), Pol et al. (2009), entre outros, revelam que o uso desse pensamento mesmo que de forma não intencional, é o diferencial entre os alunos considerados experts em Física do que os que apresentam dificuldades na compreensão dessa ciência, denominados na literatura de "novatos". Em outras palavras, um aluno com expertise em Física de certa forma recorre a seu pensamento metacognitivo, mesmo que não tenha consciência disso. Tal relação leva a entender que se for favorecida explicitamente a evocação dessa forma de pensamento em sala de aula, contribuiríamos com a aprendizagem. De fato, Hattie (2009) mostra que propostas de intervenções didáticas estruturadas a partir do uso do pensamento metacognitivo, tem apontado resultados favoráveis na aquisição do conhecimento, ainda que outros fatores também estejam associados e influenciem no sucesso escolar. Portanto, o uso desse pensamento não é o 
único fator, mas um dos agentes que contribui para potencializar a aprendizagem, especialmente em Física.

Com relação à diferença entre os alunos experts, novatos em Física e o uso do pensamento metacognitivo, menciona-se o estudo desenvolvido por Bogdanovic et al. (2015) na República Sérvia que revelou a existência de uma co-relação direta entre a consciência metacognitiva e os resultados em Física. A pesquisa analisou o desempenho de 746 estudantes na faixa etária de 15 anos por meio de questionários relacionados ao uso do pensamento metacognitivo e teste de conhecimentos específicos de Física. Como resultado apontou haver diferenças no desempenho em Física de alunos que apresentam maior consciência metacognitiva, distinto do revelado para os que não utilizam essa forma de pensamento. O teste de conhecimento em Física envolvia conhecimentos específicos na disciplina e não se limitava a resolução de problemas, o teste metacognitivo aplicado aos alunos foi o clássico Metacognitive Awareness Inventory - MAl, desenvolvido por Schraw e Dennison (1994). A esse estudo inclui-se os desenvolvidos por Gunstone (1994) e Nashon e Anderson (2004) entre outros, que apontam que o envolvimento ativo do pensamento metacognição nas atividades de aprendizagem é fundamental para o desenvolvimento de uma compreensão conceitual em Física.

O exposto tanto em termos de resultados específicos situados no âmbito da resolução de problemas, como no domínio dos conteúdos de Física, revelou que o uso do pensamento metacognitivo é um diferencial entre estudantes experts e novatos. Quanto a isso parece à literatura convergir, e considerando o caso dos alunos experts, surge a indagação sobre que aspectos associados ao pensamento metacognitivo estão presentes no momento em que eles se estruturam para resolver problemas em Física. Em outras palavras e focando apenas naqueles que recorrem ao pensamento metacognitivo, indagase sobre quais elementos são ativados de forma mais intensa.

O questionamento se dá a partir do entendimento de que os alunos com expertise em resolução de problemas recorrem mais fortemente as suas habilidades metacognitivas conforme destacado por Malone (2008), Taasoobshirazi e Farley (2013) e Ryan et al. (2016), mas, nesse contexto e considerando os diferentes elementos que integram as habilidades metacognitivas. Quais os que estão mais presentes e são ativados por eles? As habilidades metacognitivas referem-se, conforme indicado por Flavell (1979), ao controle executivo e autorregulador da ação, ou seja, aquela responsável pela operacionalização dos conhecimentos em prol da realização de uma ação. Brown (1987) infere que essas habilidades são estruturadas a partir de três elementos: planificação, monitoração e avaliação.

Tais elementos operam em conjunto e possibilitam ao sujeito controlar e autorregular a sua ação. No caso da resolução de problemas em Física, a questão posta em discussão neste trabalho situa-se no âmbito de identificar como os alunos operam com tais elementos e quais os que se revelam mais intensamente presentes neste grupo considerado com expertise na ação. Portanto, a pesquisa busca responder ao seguinte questionamento: como a metacognição se manifesta nos estudantes considerados experts na resolução de problemas em Física?

Tal questionamento leva a propor um estudo envolvendo alunos com expertise nesse tipo de tarefa e analisar a forma como procedem a sua realização, delimitando a análise em termos das habilidades metacognitivas. Desse modo o estudo apresenta como objetivo identificar a forma como estudantes experts em resolução de problemas estruturam seu 
pensamento e recorrem às habilidades metacognitivas como forma de lograr êxito na tarefa.

Para atingir ao objetivo foram selecionados estudantes de um curso de graduação em Física e que de acordo com indicação do corpo docente são considerados bons solucionadores de problemas em Física. A partir de entrevistas clínicas e do uso da técnica de protocolo verbal concomitante a realização da tarefa, foram obtidos dados que permitiram analisar quais dos elementos metacognitivos são mais utilizados pelos sujeitos e se há uma co-relação entre as indicações de que são bons revolvedores de problemas e a expertise na tarefa.

A escolha por dialogar e investigar os processos metacognitivos envolvidos nesse tipo de atividade decorre do entendimento de que tais métodos em consonância com os conteúdos beneficiam a aprendizagem em Física, pois possibilitam que os estudantes se mantenham mais atentos e vigilantes em relação à sua aprendizagem. Nesse caso e a partir dos dados emergidos desse estudo, espera-se reforçar a tese de que os professores de Física precisam favorecer o uso desse pensamento em sala de aula, especificamente nesse caso, na resolução de problemas e quais os elementos que precisam ser reforçados por eles.

Para apresentar os resultados do estudo desenvolvido, o presente texto está estruturado em seções que foram assim constituídas: a primeira refere-se à apresentação do referencial teórico que embasa o estudo e está associado à discussão dos processos metacognitivos; na seção seguinte são descritos os procedimentos metodológicos utilizados no estudo; na terceira discorre-se sobre os resultados obtidos; ao final, a título de considerações finais, são apresentadas reflexões do estudo e apontamentos de novos estudos.

\section{Referencial Teórico}

O estudo apresentado nesse texto tem sua relevância à medida que o uso do pensamento metacognitivo ou o fato dos estudantes recorrem a estratégias dessa natureza, tem se mostrado promissora na literatura. Hattie (2009) revelou em seu estudo que tais subterfúgios estão entre as dez ações que mais favorecem a aprendizagem. O autor após realizar longos estudos analisando as estratégias de ensino e quais as que apresentam maior eficácia, constatou que as metacognitivas configuram entre as dez mais eficazes. Entretanto, apesar disso, elas ainda permanecem distantes da sala de aula. Conforme já mencionado, sua utilização tem sido relegada àqueles que por alguma razão ativam espontaneamente essa forma de pensamento, o que não é comum a todos. Portanto, cabe a escola mostrar aos alunos como evocar esse pensamento e obter êxito com sua utilização. De acordo com Monereo (2001) e Rosa (2014) e outros autores, cabe ao professor associar determinadas estratégias a sua ação, como forma de favorecer que os alunos aprendam a utilizá-la.

Com relação aos estudos envolvendo o uso da metacognição em sala de aula, destacase o apontado por Zohar e Barzilai (2013) que mapearam um conjunto de investigações envolvendo os temas metacognição e educação em ciências. As autoras analisaram periódicos internacionais publicados na base de dados ERIC e em outras revistas da área, para o período de 2000 a 2012. A pesquisa identificou um total de 233 estudos apresentando o termo metacognição em seu conteúdo, sendo que 178 (76,4\%) 
apresentavam a metacognição como propósito principal do estudo e desses, 59 (43,4\%) estavam vinculados a propostas didáticas envolvendo a metacognição em sala de aula. Ainda, 55 estudos (40,4\%) referiam-se a investigações em que a metacognição foi codificada como resultados, isto é, "a metacognição foi medida como resultado de uma prática instrucional, uma intervenção instrucional ou manipulação experimental." (p. 138, tradução nossa).

O estudo realizado por Zohar e Barzilai (2013) se contrapõe a investigação desenvolvida por White (1998) que tomando como corpus a mesma base de dados, no período de 1966 a 1995 encontrou uma ausência de estudos na temática, especialmente entre 1966 a 1975; um estudo entre 1976 e 1980, 17 estudos entre 1981 e 1985; 49 estudos entre 1986 e 1990; e, 48 estudos entre 1991 e 1995. Ainda com relação à apuração de Zohar e Barzilai (2013), as autoras inferem que o tema metacognição tem configurado entre as áreas de interesse dos pesquisadores do campo da Educação em Ciências, mesmo que ainda limitado a estudos em algumas situações específicas. Dentre as que as autoras apontam como possibilidade de ampliação e de acordo com o objeto de investigação deste trabalho estão os empíricos descritivos. Esses estudos situam-se na caracterização ou exame da relação entre a metacognição e outras variáveis, como as habilidades para resolver problemas, por exemplo. Dos 178 estudos identificados, 46 encontravam-se nessa modalidade, todavia, poucos evidenciam características do modo de pensamento que alunos considerados com expertise em uma determinada área retratam no momento em que realizam suas atividades.

Entretanto, para proceder a essa análise, objeto de discussão do presente texto, faz-se necessário entender o termo "metacognição" e seus componentes, bem como, analisar quais as especificidades inerentes a cada uma delas, com destaque para as que integram as habilidades metacognitivas.

A metacognição, em linhas gerais, refere-se ao processo de "pensar sobre o pensar" ou a "cognição da cognição". Entretanto, como lembram Zohar e Barzilai (2013), desde os primeiros estudos sobre metacognição na década de 1970 com o psicólogo John Hurley Flavell, uma das questões apontadas como um entrave para que ela ganhe maior aceitação na comunidade científica, vincula-se a falta de um referencial teórico e de uma definição consensual entre os pesquisadores. A razão disso pode estar, conforme mencionado por Hacker (1998) na associação desse construto a distintos campos. Por outro lado, o autor chama a atenção para o fato de que embora exista essa nebulosidade entorno do conceito de metacognição, grande parte dos autores se mantém fiel a perspectiva definida pelo psicólogo americano, considerado precursor nos estudos dessa natureza.

Seguindo o abordado por ele, especialmente em suas obras de 1976 e 1979, e apoiando-se em pesquisadores da área de ensino de Ciências como Otero (1990), Rosa (2011), infere-se uma definição que engloba o entendimento de metacognição e suas duas componentes:

Metacognição é o conhecimento que o sujeito tem sobre seu conhecimento e a capacidade de regulação dada aos processos executivos, somada ao controle e à orquestração desses mecanismos. Nesse sentido, o conceito compreende duas componentes: 0 conhecimento do conhecimento e o controle executivo e autorregulador. (ROSA, 2011, p. 57, destaque da autora). 
Nessa definição de metacognição se manifestam as duas componentes que, segundo Ribeiro (2003) são essenciais para o entendimento da metacognição:

[...] conhecimento sobre o conhecimento (tomada de consciência dos processos e das competências necessárias para a realização da tarefa) e controle ou auto-regulação (capacidade para avaliar a execução da tarefa e fazer correções quando necessário - controle da atividade cognitiva, da responsabilidade dos processos executivos centrais que avaliam e orientam as operações cognitivas) (2003, p. 110).

Tais componentes foram especificados por Rosa (2011) ao mencionar que o conhecimento do conhecimento representa o "conhecimento que o sujeito tem sobre si próprio no que se refere à variável pessoa, tarefa e estratégia e, também, à maneira como essas interferem no resultado da cognição" (p.50). Continua a autora mencionando que "Flavell indica que esse conhecimento metacognitivo consiste, primeiramente, no conhecimento ou na opinião sobre que fatores ou variáveis agem e interagem e de que maneira afetam o curso e o resultado cognitivo." (p.50). Portanto, o conhecimento que o sujeito tem sobre seu próprio conhecimento representa a tomada de consciência de como ele julga ser em relação à ação a ser executada e em comparação com o outro. Isso envolve conhecimento de si (pessoa), da tarefa a ser executada e da estratégia a ser utilizada.

A variável pessoa é o momento em que o sujeito identifica como funciona o seu pensamento em comparação aos outros; a variável tarefa está vinculada a natureza da informação que se apresenta ao sujeito e os critérios a serem adotados por ele para sua realização; por fim, a variável estratégia representa "o momento em que o sujeito se questiona sobre o que precisa ser feito e quais os caminhos a serem seguidos para atingir o objetivo" (ROSA, 2014, p. 28). Tais variáveis interagem entre si de tal modo que, conforme mencionado por Ribeiro (2003) faz sentido dizer que, o aprendiz X, utiliza determinada estratégia, enquanto o Y outra, porque para tal estratagema lhe parece mais adequado.

O controle executivo ou autorregulador da ação, referindo-se ao que Flavell (1979) e Veemnan, Van Hout-Wolters e Afflerbach (2006) denominam de habilidades metacognitivas, representa a fase de operacionalização da ação que se encontra vinculado ao conhecimento do conhecimento, porém se difere dele por representar a etapa executiva na qual se fazem presentes distintos momentos. De acordo com Brown (1978, 1987), a regulação dos conhecimentos abrangem mecanismos autorregulatórios na realização das tarefas, como a planificação, monitoramento e a avaliação.

A planificação é aquela em que o sujeito prevê as etapas e escolhe as estratégias, em relação ao que se pretende alcançar. Brown (1987) explica que o planejamento somente poderá ocorrer à medida que o sujeito conhecer o problema em sua forma global iniciar a busca pela solução. Em termos gerais podemos dizer que quando confrontado frente a uma situação ou problema, os sujeitos estabelecem um plano que permite traçar caminhos para atingir ao objetivo proposto e que isso leva em conta seus conhecimentos sobre si, sobre a tarefa e sobre a forma de realizá-la. Sobre isso, Taasoobshirazi e Farley (2013) mostram que a planificação de uma ação enquanto elemento metacognitivo favorece o pensar sobre essa ação e identifica os mecanismos que precisam ser ativados para atingir seus propósitos.

No que se refere à aprendizagem Rosa (2014) destaca que essa operação de planificação pode ser identificada como a organização de materiais para estudo ou elaboração de um questionário, que servira como guia de estudo para o sujeito. A autora 
ressalta também que no ensino de Física, a planificação serve como um momento em que o estudante decide a forma como executar determinada tarefa e os meios utilizados para tal.

O monitoramento, por sua vez, segundo Rosa (2014) "consiste em controlar a ação e verificar se está adequada para atingir o objetivo proposto, avaliando o desvio em relação a esse, percebendo erros e corrigindo-os" (p. 39). Brown (1987) aponta para a necessidade de monitorar-se, pois, é um momento onde se testa e revisa cada procedimento executado, a fim de aprender.

Na aprendizagem pode-se interpretar, na visão de Brown (1987), como a revisão dos conhecimentos já existentes durante a construção de novos, de forma que o sujeito pode avaliar se está prosseguindo de forma certa para a construção do novo conhecimento. Para a aprendizagem a monitoração é um momento muito importante, pois envolve o estudante em uma nova verificação de seus pensamentos, por exemplo, conceitos e cálculos. Para Rosa em geral "[...] essas ações atuam como alerta aos estudantes sobre possíveis interrupções na construção do conhecimento ou na realização de uma ação, permitindo que tomem decisões de mudanças a tempo" (2014, p.39).

A avaliação, último elemento da categoria habilidade metacognitiva refere-se à verificação dos "resultados atingidos em face do fim pretendido, podendo, eventualmente, ser definida pelos critérios específicos de avaliação" (ROSA, 2014, p.39). Ela corresponde ao momento em que o aluno julga os resultados e verifica seus caminhos, analisando as escolhas e procedimentos adotados frente aos resultados encontrados. É o verificar da ação e das escolhas.

$\mathrm{Na}$ aprendizagem escolar é o momento em que os estudantes retomam e avaliam o que aprenderam, identificam como aprenderam determinado conteúdo, confrontam o resultado obtido com o objetivo cognitivo, a fim de avaliar a estratégia utilizada em termos de sua eficácia.

Esses elementos identificados como habilidades metacognitivas são apontados por Veemnan, Van Hout-Wolters e Afflerbach (2006) como um mecanismo de feedback no qual o sujeito é capaz de planejar o prosseguimento de suas ações e o desempenho na tarefa, ou para verificar que não conseguirá lograr êxito nelas e detectar sua ineficácia. Continuam os autores mencionados que é no conjunto das ações executivas que o sujeito consegue atingir seus objetivos com sucesso.

\section{Descrição metodológica da pesquisa}

A pesquisa caracteriza-se como qualitativa que na acepção de Triviños (1994) refere-se ao tipo de investigação que prioriza a interpretação e discussão dos dados de forma a buscar seu significado, tendo como base a percepção do fenômeno dentro do seu contexto. A descrição qualitativa procura captar não só a aparência do fenômeno, mas também suas essências, visando explicar sua origem, relações, mudanças e tenta intuir possíveis consequências.

Além disso, o estudo pode ser caracterizado como um estudo de caso, uma vez que adota como sujeito um grupo particular e que compartilha uma mesma realidade. A escolha pelo estudo de caso implica, de acordo com mencionado por Yin (2015), em não buscar alcançar generalizações universais, mas generalizações analíticas voltadas para a ampliação e para a generalização de teorias. 
Os dados obtidos tomaram como instrumento a utilização de protocolos verbais ou protocolos de pensamento em voz alta, que se caracteriza como uma técnica. Segundo Ericsson e Simon (1993) consiste em o sujeito verbalizar seus pensamentos ou processos cognitivos durante a realização de uma tarefa, por exemplo, a resolução de um problema, onde o aluno relata seus passos a partir de seu pensamento. Ainda para esses autores, 0 pensamento em voz alta não interfere no desempenho do sujeito, pois esse método faz com que ele necessite apenas verbalizar o que está pensando, sem requerer processos cognitivos adicionais.

Dentro dessa técnica há duas possibilidades de abordagem, a verbalização concorrente na qual o relato verbal ocorre simultaneamente à execução da tarefa, e a verbalização retrospectiva em que a verbalização ocorre na forma de relato após a realização da atividade. Considerando o objetivo do estudo que consiste em analisar as manifestações dos alunos durante a realização de problemas, optou-se pela primeira abordagem e por meio de gravações de áudio registrou-se a fala dos estudantes. Essa abordagem se revelou uma possibilidade em virtude de permitir capturar os dados no momento em que o sujeito está processando seu pensamento, ou seja, simultaneamente a realização da tarefa.

A característica de capturar dados no momento em que eles estão sendo produzidos é particularmente importante em processos que buscam analisar as habilidades metacognitivas utilizadas pelos sujeitos durante a execução de tarefas, conforme mencionado por Veenman (2005). De acordo com o autor há dois métodos de avaliação dos processos metacognitivos: um off-line e outro on-line. Métodos off-line são aqueles em que a avaliação ocorre antes ou após o desempenho da tarefa; enquanto que as avaliações on-line são obtidas durante o desempenho da tarefa. Ainda seguindo o mencionado por Veenman, os métodos on-line parecem ser mais eficientes na avaliação do desempenho em relação aos métodos off-line, mesmo quando estes são administrados retrospectivamente ao desempenho das tarefas.

Ainda em relação à escolha do protocolo verbal na abordagem da verbalização concomitante, destaca-se que ele seguiu o proposto por Ericsson e Simon (1993) e teve sua aplicação estruturada de modo a considerar os três elementos apontados pelos autores. Tais elementos referem-se a aspectos que devem ser observados no momento da obtenção dos dados e são assim descritos: a) cenário - escola de local em que o sujeito esteja confortável e se sinta livre de qualquer coerção; b) seleção dos sujeitos - ter a precaução de selecionar sujeitos que conheçam a tarefa e que apresentam características distintas entre si; c) instrução - fornecer instruções claras e tomar o cuidado para não induzir o sujeito a um desempenho pretendido pelo pesquisador.

A partir dessas escolhas e considerando as características da técnica selecionada, projetou-se um estudo envolvendo estudantes de graduação de um curso de licenciatura em Física de uma universidade localizada na região norte do Rio Grande do Sul. A amostra de sujeitos foi obtida por meio da indicação dos professores sobre quais alunos apresentavam expertise na resolução de problemas em Física, segundo as características que definem esse grupo e já mencionadas nesse estudo. A indicação apontou para um grupo de seis estudantes que foram identificados como os sujeitos da pesquisa. Vale lembrar que a escolha desse grupo não levou em consideração apenas os resultados de uma avaliação específica, mas sim a análise das indicações de cinco professores do curso, que ministram disciplinas específicas de Física (Mecânica Clássica, Termodinâmica, Eletromagnetismo, Mecânica Ondulatória e Física Moderna). 
Frente às indicações dos professores, procedeu-se a seleção dos que haviam sido indicados por pelo menos três deles. Dessa forma, constituíram-se os sujeitos do estudo, seis estudantes do curso que apresentam expertise em resolução de problemas em Física. $O$ universo total de alunos matriculados no curso no momento da realização da pesquisa, segundo semestre de 2017, estava constituído por 83 acadêmicos. Dois alunos foram indicados por dois dos professores e constituíram a amostra do teste piloto. Todos os seis sujeitos apresentam idade entre 18 e 21 anos, realizam o curso no horário noturno e participam de projetos de pesquisa, extensão ou integram o Programa Institucional de Bolsa de Iniciação à Docência - PIBID. Em termos de gênero o estudo, incluindo o teste piloto, envolveu cinco estudantes declaradamente do sexo masculino e uma do sexo feminino.

A atividade realizada com os oito sujeitos ocorreu na forma de entrevista clínica e foi integralizada pela resolução de três problemas de Física, selecionados por cada sujeito frente a um conjunto de cinco problemas apresentados, os quais envolviam diferentes áreas da Física como Mecânica, Hidrostática, Calorimetria, Ondulatória e Eletrodinâmica. O teste piloto realizado com os dois estudantes serviu para proceder a ajustes na escolha dos problemas e nas instruções fornecidas no início da tarefa.

Para a realização dos testes, os sujeitos foram chamados individualmente e após ouvirem as instruções e assinarem o termo de consentimento livre e esclarecido, iniciaram a atividade. Para isso, foi solicitado aos alunos que explicitassem o modo como estavam procedendo para resolver o problema, como realizavam suas escolhas e/ou manifestações de pensamento que lhes vinham a mente durante a resolução dos mesmos. Foi lembrado a eles que as manifestações deveriam ser livres, podendo inclusive referir-se a outros assuntos que não apenas a atividade que thes era apresentada.

Além da gravação em áudio, os alunos foram observados por uma das pesquisadoras que registrou sobre manifestações de pensamento metacognitivo dos estudantes. $O$ uso da observação com registro é indicado por Marconi e Lakatos (2003) como um instrumento para coleta de dados onde é possível conseguir informações, utilizando os sentidos na obtenção de determinados aspectos da realidade, ela não consiste apenas em ver e ouvir, mas também em examinar os fatos ou fenômenos. A observação ainda pode ajudar o pesquisador a identificar e obter provas de objetivos sobre os quais os indivíduos não têm consciência, mas que orientam seu comportamento. Tais registros das observações foram utilizados apenas como complemento, quando necessário, as gravações de áudio.

Os seis alunos resolveram três problemas cada um, cuja análise que segue na continuidade está baseada na fala dos sujeitos acrescida da observação de uma das pesquisadoras. Estas falas estão representadas em itálico ao longo do texto e indicadas pela letra "E", seguido de um número que inicia em "1" e acaba em "6". A distribuição seguiu a ordem das entrevistas e o uso dessa identificação tem o intuito de diferenciar os sujeitos. Por fim, destaca-se que nas citações utilizadas ao longo do texto, referentes a fala dos sujeitos respeitou-se a linguagem utilizadas por eles, suprindo-se apenas os vícios de linguagem, como recomendado por Duarte (2004).

\section{Análise e discussão dos dados}

Para proceder à análise dos dados, recorre-se a sua categorização seguindo o proposto por Brown (1987) em termos dos elementos que integram a componente, controle 
executivo e autorregulador que de acordo com Veemnan, Van Hout-Wolters e Afflerbach (2006) representam as habilidades metacognitivas, foco do presente estudo.

Ainda em termos da análise dos resultados destaca-se que o mesmo seguiu o proposto por Bardin (2004) em termos da técnica da análise de conteúdo e buscou por meio das falas dos sujeitos analisar as comunicações decorrentes das ações que estavam sendo executadas. Como lembra a autora, essa técnica busca descrever e interpretar o conteúdo dos dados coletados, conduzindo a descrições que possibilitam interpretar as mensagens e atingir uma compreensão dos significados de forma mais ampla que a leitura simples e direta dos dados. Portanto, o estudo que segue toma o exposto por Bardin e infere que a análise decorre da leitura do material em um nível mais aprofundado que sua interpretação literal.

\section{Planificação}

Nesta categoria estão associados os procedimentos dos estudantes no momento em que leem os problemas propostos e iniciam a busca pela solução. Conforme mencionado a planificação está associada ao planejamento e é composto pelas metas estabelecidas para executar com êxito a ação. Nesse momento, como lembra Rosa (2014) é ativado conhecimento relevante, selecionando estratégias adequadas e avaliado o tempo disponível para isso. Ainda, planejar inclui pensar sobre o que se precisa para alcançar um objetivo e sobre como se pretende alcançá-lo.

Neste sentido, observou-se que os alunos executam atividades de planejamento no momento em que analisam o problema e destacam as palavras ou similares importantes para a solução, evidenciam a incógnita, ou seja, o que problema "quer saber"; traçam diagrama para auxiliar na compreensão; e, manifestam expressões como "eu preciso fazer", "antes eu preciso ver", "aqui está pedindo que" ou "nesse tipo de problema eu preciso antes".

Os seis alunos participantes do estudo mostraram claramente essas ações durante a realização dos três problemas propostos. Entretanto, o destaque das expressões no enunciado ficou restrito a três deles. Como exemplo das manifestações dos alunos durante a realização dos problemas e identificadas como de planificação, apresenta-se a seguir parte da narrativa dos investigados:

E1 no primeiro problema: [...] tá eu vou precisar saber nesse problema a velocidade do carro depois da colisão, então preciso das massas porque eles estavam se deslocando com velocidades diferentes.

E2 no quinto problema: [...] então eu sei que a resistência do primeiro é 20 e a do segundo é 45, então o que eu tenho que achar é a resistência do terceiro, é isso que o problema quer, eu gosto primeiro, quando vou fazer um problema, deixar bem claro o que eu estou procurando.

E3 no quinto problema: Primeiro eu vou anotar os valor das correntes e agora das resistências e do que eu quero saber no problema, no caso a resistência desse resistor. Depois vou desenhar o circuito, porque aí entendo melhor como fazer.

E4 no segundo problema: Eu preciso achar a força máxima suportada pelo fundo do reservatório e pra isso eu preciso achar a pressão e a área. 
Agora então vou precisar da pressão e pra isso eu uso a densidade e a altura. A área porque o problema fala que a base é mencionada valor dessa área.

E5 no quarto problema: Antes eu preciso ver o que o problema pede que neste caso é ... a velocidade da onda transversal que está se propagando na corda. Então vou fazer o desenho [...] aqui estão os valor indicados no problema e pra isso eu preciso [...].

E6 no quinto problema: pelo valor das correntes eu deduzo que esse circuito esta em paralelo e não em série [...] antes de iniciar eu preciso ver o que o problema está pedindo [...] antes vou fazer o desenho porque ele vai me mostrar onde estão esses resistores e como sei o comportamento da corrente e da voltagem no circuito vou conseguir descobrir o que quero $[\ldots]$

Os exemplos ilustram trechos das falas dos estudantes e permitem identificar que a planificação faz parte de sua organização para resolver a atividade. Retomando o mencionado por Taasoobshirazi e Farley (2013) tem-se que o planejamento metacognitivo inclui pensar sobre o que um problema está perguntando, quais as possíveis estratégias para resolvê-lo e como implementar com sucesso essas estratégias. Schraw, Crippen e Hartley (2006), por sua vez, ressaltam a importância desse elemento na resolução de problemas e mencionam que os experts destinam mais tempo a essa etapa que os novatos. De fato, o que foi observado no estudo evidencia que os experts passam um tempo planificando suas ações, definido o caminho para atingir o objetivo, somente depois partem para a resolução.

Outro aspecto enaltecido nessa etapa foi a necessidade de desenhar a situaçãoproblema apresentada. Os seis alunos recorrem a essa estratégia nos três exercícios, exceto quando estavam realizando o segundo deles que já trazia o desenho como parte do problema apresentado. O uso de diagramas é ressaltado por Taasoobshirazi e Farley (2013) como uma das principais diferenças entre experts e novatos em Física: "Antes de resolver um problema, os experts tendem a desenhar um diagrama de corpo livre. Os novatos, ao contrário, tendem a se concentrar apenas na criação e resolução de equações" (p. 54, tradução nossa). Continua os autores mencionando que

os novatos muitas vezes não conseguem desenhar diagramas de corpo livre adequados porque não entendem os conceitos e princípios subjacentes aos problemas que estão resolvendo [...] Assim, à medida que os novatos progridem para a expertise e ganham mais conhecimento conceitual, o uso de diagramas de corpo livre provavelmente aumentará, assim como a qualidade desses diagramas. (p. 54, tradução nossa).

Portanto, de acordo com os autores o fato dos experts recorrem a essa estratégia é um indicativo de seu domínio conceitual em Física, aspecto que já havia sido enaltecido por Larkin (1983) ao afirmar que os experts partem para a solução de um problema somente após terem clareza da representação desse problema ou da situação Física envolvida. Embora o autor tenha se referido a uma representação mental criada pelo estudante, seu esquema no papel é um indicativo de que essa representação está em curso. 


\section{Monitoramento}

Nessa categoria estão inclusos os procedimentos dos alunos em relação ao acompanhamento durante a execução da atividade. Este elemento envolve as habilidades necessárias para controlar o processo de resolução do problema, garantindo que as ações façam sentido dentro das estruturas cognitivas selecionadas para a atividade. Além disso, possibilita julgar se a compreensão é suficiente e se há conflito entre as conexões de pensamento estabelecidas.

No entender de Ali et al. (2016) o monitoramento é caracterizado como aquele que decorre do acompanhamento dos sujeitos durante a realização das ações. Ou seja, quando os sujeitos verificam mais de uma vez seu pensamento, seus cálculos, conceitos, planos de ação e outros. No caso da resolução de problemas isso está representado pela verificação do procedimento utilizado, dos cálculos realizados e do percurso em andamento frente ao objetivo pretendido. Além disso, é representado pelo fato dos alunos voltarem ao enunciado e lerem novamente o problema como forma de verificar se estão realizando os procedimentos corretos frente ao fim pretendido.

$\mathrm{Na}$ fala dos estudantes investigados, foi possível verificar a presença deste elemento metacognitivo, contudo, em uma proporção menor que o elemento anterior. Nas falas percebe-se que eles mantêm claro o objetivo da ação ou a incógnita que desejam obter o valor, contudo, poucas vezes recorrem ao enunciado como forma de verificar suas escolhas. Dos seis alunos identificou-se que todos têm claro o objetivo a ser alcançado com o problema e constantemente reportam-se a ele, entretanto, apenas dois alunos voltaram a ler o problema novamente a fim de verificar suas escolhas.

Os extratos de falas a seguir ilustram a presença do monitoramento durante a resolução dos problemas propostos:

E1 no terceiro problema: o calor específico envolve a massa que está em gramas então não posso usar em quilograma [...] se eu considerar que há troca de calor só entre gelo e água então eu tenho que um cede e outro recebe, mas o gelo precisa mudar de fase, então preciso somar essas quantidades de calor que são diferentes, porque calor pra derreter é muito maior do que pra subira temperatura.

E2 no primeiro problema: como é uma colisão inelástica os dois ficaram juntos e ai... o coeficiente de restituição é... tá mas não é por ai, estou fazendo errado.

E3 no terceiro problema: eu sei que preciso igualar a troca de calor e que a variação é de 15 grau Celsius para a água e 5 para o gelo, mas que o gelo precisa derreter e pra isso ele precisa de maior quantidade de calor. Deixa eu ver se estou pensando correto, a água cede calor e o gelo ganha, isso .. Ele precisa derreter e chegar a 5.

E4 no primeiro problema: ta, mas eu fiz errado porque ao ler o enunciado de novo vi que eu esqueci de transformar o valor da velocidade de quilômetros por hora para metros por segundo. [...] é assim mesmo porque é uma colisão inelástica e nesse caso os dois vão ter a mesma velocidade no final... Ah então tá certo o que eu fiz. 
E5 no segundo problema: eu não lembro a fórmula, mas eu sei que a força nos líquidos está relacionado à sua densidade e a altura do líquido porque [...]. Eu estabelecendo uma relação entre as grandes eu chego a resposta [...] aqui eu achei a pressão, mas o que o problema quer é a força, então vou voltar e olhar de novo.

E6 no terceiro problema: tem algo errado aqui, porque não pode... Isso vai dar negativo e como vou achar a massa negativa. Olha aqui o valor de massa de gelo que vai dar. Não é por aqui, deixa eu voltar aqui.

O monitoramento como elemento metacognitivo presente em estudantes experts em resolução de problemas em Física, toma como pressuposto o mencionado no estudo de Chi et al. (1989). Nesse estudo os autores mostram que bons solucionadores monitoram ativamente e com precisão sua compreensão e produzem autoexplicações de suas ações, o que os auxilia na detecção de falhas e incompreensões. $\bigcirc$ que foi percebido na ação dos seis estudantes é que eles produzem esses autoconhecimentos de suas ações, e mantêm-se atentos aos seus objetivos, entretanto, poucas vezes efetuam paradas e analisam essas escolhas.

Rosa (2011) em um estudo que envolveu momentos explícitos de evocação do pensamento metacognitivo, evidenciou que o monitoramento não é uma tarefa fácil e nem todos explicitam essa ação durante a realização e tarefa, embora estejam realizando. No estudo foi apontado que o elemento metacognitivo mais difícil de ser avaliado em termos de sua presença é o monitoramento, pois dificilmente os alunos param e refletem sobre suas ações, mesmo os que apresentam essa característica intrínseca ao seu pensamento e ação.

\section{Avaliação}

A última categoria em discussão envolve o elemento metacognitivo avaliação e pautase pela ação de verificar o realizado, de analisar se as escolhas e os caminhos trilhados estão de acordo e permitiram chegar à solução do problema proposto. De acordo com o apresentado nesse texto, a avaliação refere-se a um dos produtos e processos de aprendizagem, ou seja, é a capacidade de avaliar a utilidade das estratégias de aprendizado adotadas.

De acordo com Rosa (2011), esse elemento se manifesta nos estudantes no momento em que "ao chegar ao final de uma atividade, percebem, por exemplo, a coerência entre os resultados e o objetivo [...] quando se dão conta de que devem rever o executado de modo a identificar possíveis falhas na operação." (p.57). Continua a autora mencionando que esse componente merece destaque especial em atividades como a resolução de problemas, porque é o confronto entre a interpretação inicial e o resultado, ainda, possibilita ao estudante detectar falhas e possíveis equívocos de pensamento ou ação.

No estudo, este elemento esteve associado à identificação de que os alunos ao final dos problemas retornam ao enunciado e avaliam se o valor encontrado condiz com o solicitado. Além disso, analisam reflexivamente o percurso executado e verificam se havia outra possibilidade de solução para a situação-problema apresentada.

A análise das gravações evidencia que os seis alunos nos três problemas propostos procedem a avaliação dos resultados obtidos frente ao solicitado no enunciado. Eles, ao final da atividade, retornam ao problema e confrontam a resposta com a situação 
apresentada, demonstrando uma característica de utilização do pensamento metacognitivo. Em termos da reflexão sobre o caminho escolhido para resolver o problema, os seis alunos procederam a essa ação, denotando uma preocupação com analisar a situação apresentada e as suas escolhas, especialmente em verificar suas estratégias e seus conhecimentos.

Os trechos a seguir ilustram o mencionado:

E1 no terceiro problema: então fica 1800g a massa do gelo, ta, mas não é isso, porque a massa da água é $500 \mathrm{~g} . .$. . A sei eu errei aqui, porque eu escolhi calcular separado e o melhor seria fazer tudo ao mesmo tempo.

E2 no primeiro problema: vou utilizar meu método de verificar se a resposta está certa [...] olha aqui eu poderia ter feito por energia e não por quantidade de movimento [...] mas tá certo, fez sentido pra mim, porque o que eu precisava é a velocidade do carro.

E3 no quinto problema: já sei que está certo porque eu tenho uma corrente de 10 Ampère passando pelo este resistor e aí divide a corrente 2,5 A para um e 7,5 A para o outro, porque eles estão em paralelo [...] então tá certo, porque é fácil achar a resistência depois disso.

E4 no segundo problema: o resultado que eu achei fecha porque está pedindo a força, só que eu poderia ter feito de outra forma, agora olhando aqui vi que já tem a área [...] deixa eu ver, se eu fizer assim... tá, também dá, mas eu pensei um pouco diferente e os dois jeito vão dar a mesma coisa, só que assim eu... acho teria sido mais fácil.

E5 no terceiro problema: deixa ver... isso é mais ou menos dez pedrinhas de gelo e isso abaixa 10 gramas de água. O problema é que eles estavam a 15 graus, mas acho que é isso, pensando agora, acho que faz sentido essa questão.

E6 no terceiro problema: tá certo porque eu fiz o equilíbrio em que a soma é zero, tenho um, que é dois, porque tem gelo e depois água, que cede e outro que recebe. [...] poderia ter calculado separado, mas só da pra fazer assim, recebe-cede, deixa ver, é isso mesmo.

Muitas das falas dos alunos são próximas as classificadas como monitoramento, entretanto, a distinção para entre elas reside no fato de que a avaliação é uma manifestação do aluno ao final da atividade, de modo a avaliar o resultado final do problema e voltar e olhar as estratégias utilizadas. O monitoramento, ao contrário, é aquele executado durante a atividade, quando o resultado final da ação ainda não esta em discussão. Sobre essa avaliação durante o monitoramento e sua distinção como avaliação ao final do processo, Schraw e Dennissn (1994) inferiram a necessidade de incluir um novo elemento aos elencados pro Brown (1987) como forma de supervisionar/avaliar a ação durante a sua execução e não apenas ao final. Para os autores os estudantes executam essa avaliação e verificação durante a ação e não apenas ao final dela.

Entretanto, restringindo o estudo ao proposto por Brown (1987) tem-se que os alunos analisados realizaram o processo de reflexão sobre a ação executada e demonstraram capazes de pensar nos resultados e avaliar o percurso e as escolhas realizadas. Como apontado por Rosa (2011) "é na avaliação que os estudantes mostram ter aprendido ou não, 
podendo proceder a uma autoavaliação dos conhecimentos adquiridos" (p.231). Ainda no entender da autora, a avaliação enquanto elemento metacognitivo "representa a possibilidade de consolidação de um processo de qualificação da aprendizagem" (p.231). Característica que se revelou presente nos resultados desta pesquisa.

\section{Considerações Finais}

O estudo desenvolvido possibilitou analisar a forma com os experts se estruturam na busca por solucionar as atividades que lhes são propostas, especialmente em termos dos recursos metacognitivos. Desses recursos, os avaliados no estudo foram planificação, monitoramento e avaliação, sendo que os seis sujeitos envolvidos na pesquisa manifestaram recorrerem a esses elementos durante toda a execução da atividade. Dentre eles o mais difícil de ser detectado no estudo foi o monitoramento, especialmente no decorrer do problema, os alunos voltam ao enunciado como forma de verificar/avaliar o procedimento em execução. Os demais quesitos analisados se mostraram amplamente integrados ao processo de resolução dos problemas propostos.

Neste sentido, as características identificadas no estudo se revelam importantes de serem consideradas pelos professores em sala de aula no momento de planejar suas aulas. Ou seja, as manifestações dos experts podem ser estendidas aos que apresentam dificuldades neste tipo de atividade, uma vez que elas favorecem a compreensão dos processos necessários para lograr êxito nesse tipo de atividade.

Sobre isso, Taasoobshirazi e Farley (2013) mencionam que há uma falta de pesquisa que examine as relações entre os elementos metacognitivos, bem como há falta de pesquisa indicando quais desses elementos são mais importantes para o sucesso de resolução de problemas. Como resultado, os professores de Física não sabem o que deve ser focado durante a instrução e o que é menos importante.

Ainda considerando a fala dos autores, destaca-se que há pouca pesquisa sobre o papel que a motivação desempenha na influência da resolução de problemas por experts. A motivação, juntamente com as emoções e a metacognição representam elementos fundamentais na aprendizagem, particularmente em Física, como mostrou González, Fernández e Paoloni (2017). Tais variáveis são determinantes em termos de elevar o engajamento e a performance dos estudantes. Além disso, Ericsson (2006) mostra que alunos altamente motivados envolvem-se de maneira persistente na prática deliberada que leva à expertise. O que pode representar uma nova enseada aos pesquisadores preocupados em qualificar o processo de aprendizagem em Física, mais especificamente em potencializar a capacidade de resolução de problemas.

\section{Referenciais}

ALI, Marlina; TALIB, Corrienna-Abd; HASNIZA Ibrahim, Nor; SURIF, Johari; HALIMABDULLAH, Abdul. The Importance of Monitoring Skills in Physics Problem Solving. European Journal of Education Studies, v.1, n,3, p.1-10, 2016.

BARDIN, Laurence. Análise de conteúdo. Lisboa: Edições 70, 2004. 
BOGDANOVIC, Ivana; OBADOVIC, Dusanka Z.; CVJETICANIN, Stanko; SEGEDINAC, Mirjana; BUDIC, Spomenka.Students' Metacognitive Awareness and Physics Learning Efficiency and Correlation between Them. European Journal of Physics Education, v.6, n.2, p.18-30, 2015

BROWN, Ann L. Knowing when, where, and how to remember: a problem of metacognition. In: GLASER, Robert (Ed.). Advances in instructional psychology. Hillsdale, New Jersey: Lawrence Erlbaum Associates, 1978. v. 1. p. 77-165.

BROWN, Ann L. Metacognition, executive control, self-regulation, and other more mysterious mechanisms. In: WEINERT, Franz E.; KLUWE, Rainer H. (Eds.). Metacognition, motivation and understanding. Hillsdale, New Jersey: Lawrence Erlbaum Associates, 1987. p. 65-116.

CHI, Michelene T.; GLASER, Robert; REES, Ernest. Expertise in problem solving. In: STERNBERG, Robert J. (Ed.). Advances in the psychology of human intelligence. v. 1. Hilsdale, N.J.: Erlbaum, 1982.

CHI, Michelene T.; BASSOK, Miriam; LEWIS, Matthew W.; REIMANN, Peter; GLASER, Robert. Self-explanations: How students study and use examples in learning to solve problems. Cognitive Science, v.13, p.145-182, 1989.

DUARTE, Rosália. Entrevistas em pesquisas qualitativas. Educar em Revista, Paraná, n. 24, p. 213-155, 2004.

ERICSSON, K. Anders; SIMON, Herbert. A. Protocol analysis: verbal reports as data. Cambridge: MIT Press, 1993.

ERICSSON, K. The influence of experience and deliberate practice on the development of superior expert performance. In: ERICSSON K. Anders; CHARNESS Neil; FELTOVICH Paul J.; HOFFMAN, Robert R. (Eds.).Cambridge handbook of expertise and expert performance. Cambridge, UK: Cambridge University Press, 2006, p. 685-706.

FLAVELL, John Hurley. Metacognitive aspects of problem solving. In: RESNICK, Lauren B. (Ed.). The nature of intelligence. Hillsdale, New Jersey: Lawrence Erlbaum Associates, 1976.p.231-236.

FLAVELL, John Hurley. Metacognition and cognitive monitoring: a new area of cognitive developmental inquiry. American Psychologist,v. 34, n.10, p.906-911, 1979.

GONZÁLEZ, Antonio; FERNÁNDEZ, María-Victoria C.; PAOLONI, Palola-Verónica. Hope and Anxiety in Physics Class: Exploring Their Motivational Antecedents and Influence on Metacognition and Performance. Journal of Research in Science Teaching, v.54, n.5, p. 558585, 2017.

GUNSTONE, Richard F. The importance of specific science content in the enhancement of metacognition.In: FENSHAM, Peter J.; GUNSTONE, Richard F.; WHITE, Richard T. (Eds.). The content of science: A constructivist approach to teaching and learning. Washington: Falmer, 1994. p. 131-146.

HACKER, Douglas J. Definitions and empirical foundations. In: HACKER, Douglas J; DUNLOSKY, John; GRAESSER, Arthur. Metacognition in educational theory and practice. Mahwah, New Jersey: Lawrence Erlbaum Associates, 1998. p. 1-23. 
HATTIE, John. Visible learning: A synthesis of over 800 meta-analyses relating to achievement. New York, NY: Routledge, 2009.

KLUWE, Rainer $\mathrm{H}$. Executive decisions and regulation of problem solving behavior. In: WEINERT, Franz E.; KLUWE; Rainer H. (Eds.). Metacognition, motivation and understanding. Hillsdale, NJ: Lawrence Erlbaum Associates, 1987. p.31-64.

LARKIN, Jill H. The role of problem representation in physics. In: GENTNER, Dedre; STEVENS, Albert L. (Eds.). Mental Models. Hillsdale, New Jersey: Lawrence Erlbaum Associates, 1983. p. 75-98.

MALONE, Kathy L. Correlations among knowledge structures, force concept inventory, and problem-solving behaviors. Physical Review Special Topics - Physics Education Research, v.4, n.2, 2008. p.020107-1- 15 .

MARCONI, Marina de Andrade; LAKATOS, Eva Maria. Fundamentos de metodologia científica. 5. ed.São Paulo: Atlas, 2003.

MOREIRA, Marco Antonio. Unidades de Enseñanza Potencialmente Significativas. Aprendizagem Significativa em Revista, v. 1, p. 43-63, 2011.

MONEREO, Carles. La enseñanza estratégica: enseñar para la autonomía. In: MONEREO, C. Ser estratégico y autónomo aprendiendo. Barcelona: Graó, 2001. p. 11-27.

NASHON, Samson; ANDERSON, David. Obsession with ' $g$ ': A metacognitive reflection of a laboratory episode. Alberta Journal of Science Education, v.36, n.2, p.39-44, 2004.

POL, Henk J.; HARSKAMP, Egbert G.; SUHRE, Cor J. M.; GOEDHART, Martin J. How indirect supportive digital help during and after solving physics problems can improve problemsolving abilities. Computers \& Education, v.53, p.34-50, 2009.

OTERO, José C. Variables cognitivas y metacognitivas en la comprensión de textos científicos: el papel de los esquemas en el control de la propia comprensión. Enseñanza de las Ciencias, v. 8, n. 1, p. 17-22, 1990.

REIF, Frederick; LARKIN, Jill H. Cognition in scientific and everyday domains: comparison and learning implications. Journal of Research in Science Teaching, v.28, n.9, p.733-760, 1991.

RIBEIRO, Célia. Metacognição: um apoio ao processo de aprendizagem. Psicologia: reflexão e crítica. 2003. Disponível em: <http://www.scielo.br/pdf/prc/v16n1/16802.pdf >. Acesso em: 18 maio 2017.

ROSA, Cleci T. Werner da. A metacognição e as atividades experimentais no ensino de Física. 2011. Tese (Doutorado em Educação Científica e Tecnológica) - Universidade Federal de Santa Catarina, Florianópolis, Brasil, 2011.

ROSA, Cleci T. Werner da. Metacognição no ensino de Física: da concepção à aplicação. Passo Fundo: Editora da Universidade de Passo Fundo, 2014.

RYAN, Qing X.; FRODERMANN, Evan; HELLER, Kenneth; HSU, Leonardo; MASON, Andrew. Computer Problem-Solving Coaches for Introductory Physics: Design and Usability Studies. Physical Review Physics Education Research, v.12, n.1, p.010105-1-010105-17, 2016.

SCHRAW, Gregory; DENNISON, Rayne Sperling. Assessing metacognitive awareness. Contemporary Educational Psychology, v.19, n.4, p.460-475, 1994. 
SCHRAW, Gregory; CRIPPEN, Kent J.; HARTLEY, Kendall. Promoting Self-Regulation in Science Education: Metacognition as Part of a Broader Perspective on Learning. Research in Science Education, v.36, n.1-2, p.111-139, 2006.

TAASOOBSHIRAZI, Gita; FARLEY, John. A multivariate model of physics problem solving. Learning and Individual Differences, v.24, p.53-62, 2013.

TRIVIÑOS, Augusto N. S. Introdução à pesquisa em ciências sociais: a pesquisa qualitativa em educação. 4ed.São Paulo: Atlas, 1994.

VEENMAN, Marcel V. J. The assessment of metacognitive skills: What can be learnedfrom multimethod designs? In: MOSCHNER, Barbara; ARTELT, Cordula (Eds.). Lernstrategien und metakognition: Implikationenfürforschung und praxis. Berlin: Waxmann, 2005. p.75-97.

VEENMAN, Marcel V. J.; VAN HOUT-WOLTERS, Bernardette H. A. M.; AFFLERBACH, Peter A.. Metacognition and learning: Conceptual and methodological considerations. Metacognition and Learning, v.1, n.1, p. 3-14, 2006.

ZOHAR, Anat; BARZILAI, Sarit. A review of research on metacognition in science education: current and future directions. Studies in Science Education, v.49, n.2, p.121-169, 2013.

YIN, Robert K. Estudos de caso: planejamento e métodos. Porto Alegre: Bookman, 2015. 